

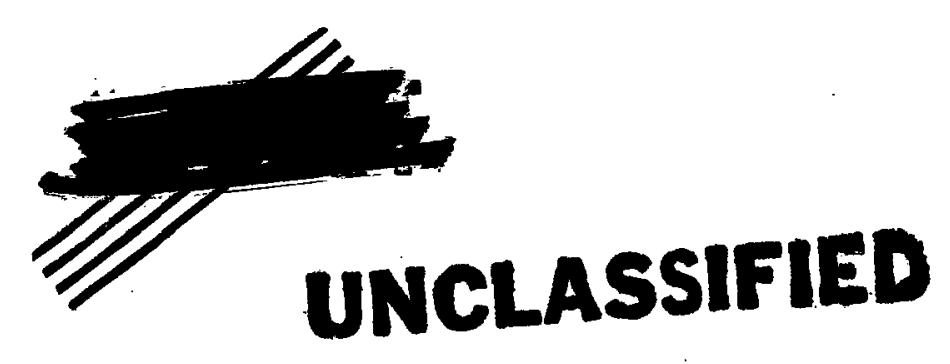

THE INEIRGY SPLCIRUSA OF FISSION NLUIRONS FROA 235

\section{Experimental Arrangenent:}

A proton beam of $2 \mathrm{IN}$ energy was allowed to fell on a target of metaliic lithiun, producing neutrons whose energies were of the orcier of $100 \mathrm{kV}$. The target was surrounded by paraffin to slow down some of these neutrons, the total quantity of paraffin being about 50 grams. A sphere of metallic uranium, 2 inches in diameter, was placed at one side of the pariafin, and the cloud chamber was placed on the same side at a distance of 6 inches from the uranium. The arrangenent is show in Fig. 1 .

The cloud chamber was $26^{\prime} \mathrm{cm}$ in dianeter and of heavy construction to withstund severnl atmospheres jressure inside. Photographs were taken with a stereoscopic mirror arrangement to 2.170 w reprojection of the tracks in sp:ce. The illuminated region was $5 \mathrm{~cm}$ deep. $\mathrm{A}$ strip $9 \mathrm{cn}$ wide extending from front to rear of the ch:mber was visible in both stereoscopic photographs. Tracks were produced only during the sensitive tine of the chamber by adjusting the timing of a shutter in the path of the proton beam.

D.sta:

In the first run, the cloud chamber was filled with methane to two atmospheres pressure. 1750 photographs were taken with the above arrangement and 600 photographs were taken to see if any noutrons other than fission neutrons were being photographed. The bacisground runs were taken by (a) removing the uranium, (b) by putting lead in place of the uranium, and (c) by reducing the energy of the proton beam below the threshold for production of neutrons in the lithium target. The baciground was found to amount. to only'a fei percent.

Tracks were me:2sured only when they were rithin $15^{\circ}$ of the direction of the fission neutrons. The angle could not be determined accurately for the shortest traciss so tracks shorter than 1 cin wrere excluded fron the final results. This laft the part of the spectrum below I iN wateternined. Because of the possibility that a large number of neutrons might be enitted with velocities nearly the same as the velocities of the fission irrog-

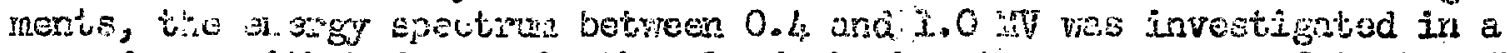
second run with hydrogen in the cloud chamber to a pressure of 2 atmospheres. 2035 photographs were taken rith the uranium in place and 1060 photographs were taken with lead replacing the uranium 


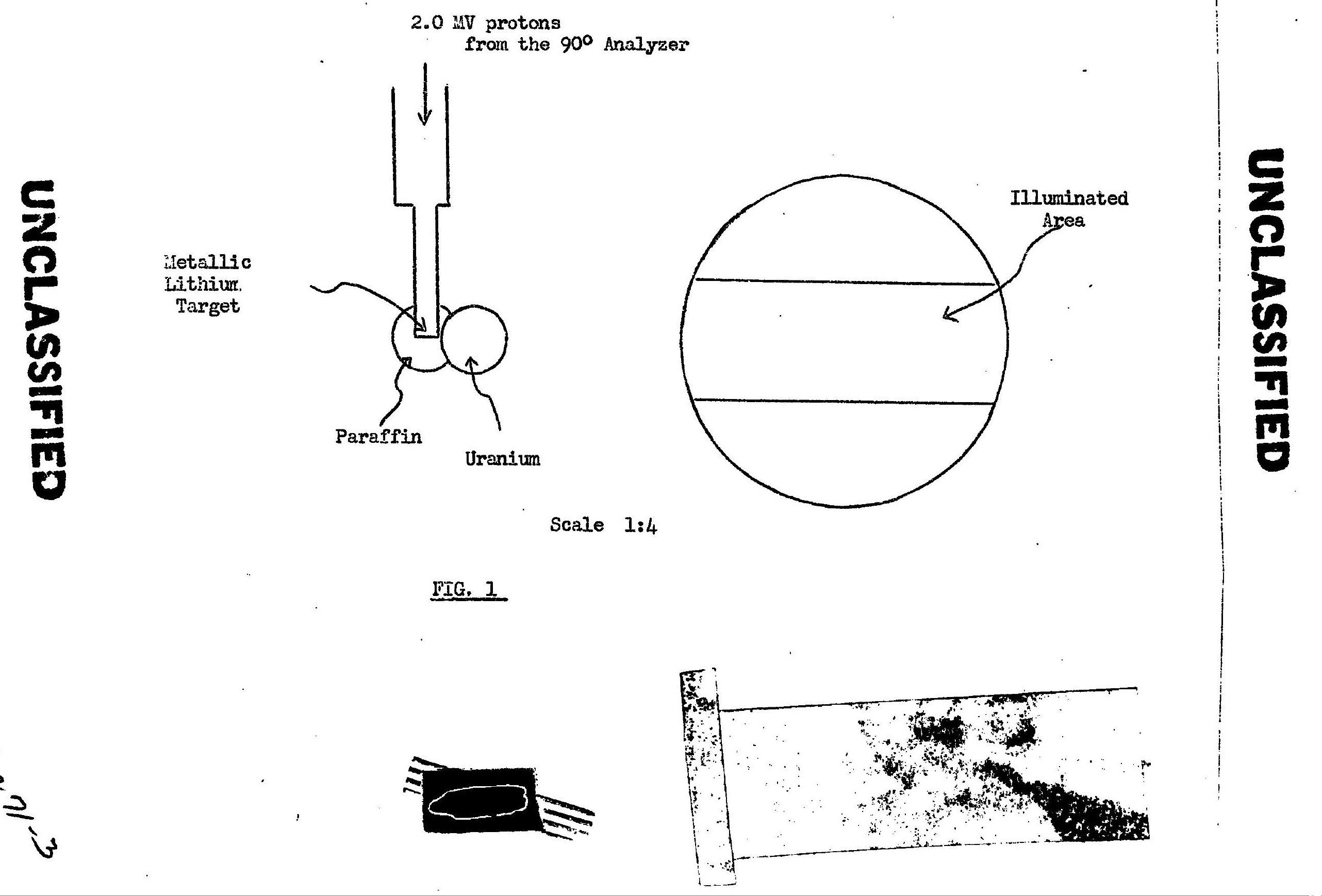




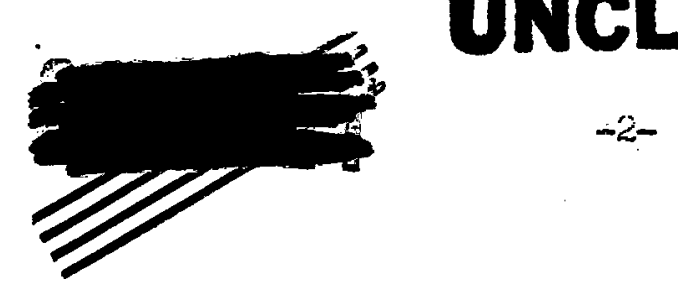

A third run wis taken with the cloud chamber filled with ethane to two atmospheres. About 450 photographs had been tiken when the experinent was discontinued. No buckground runs were included, but the bacisground was siall in methane and no serious error is made by assuming that it is the same percentiage in ethane.

The lengths of all recoil tricis visible in the photogriphs vere measured to half a millineter. Trucks which made an angle grenter than $15^{\circ}$ with the line from the midale of the uranium sphere viere excluied. It mas also required thit both ends of the track be sharp and not too neir the valls of the cloud chambor. The lengths in the cloud chanber raixture vere converted to lengths in stundsrd air. The stopoing power of each cloud chamber mixture of gas and $95 \%$ ethyl alcohol vapor wis detcrmined from the pressure as read on a bourdon type giage sisen the cloud chanber was expanded and fron the atonic stopping powers as given by Livingston and Bethel. it low energies the atomic stopping powers vary rapidly with energy. Therefore, for the hydrogen ditt, al stopping power curve was plotted and used to change lengths to ranges in stindard air. In the other mixtures the stopping power was calculated for 5 ch protons and was considered constant.

The purity of each gas used wis checked by a clensity determination. The density of the methane indicated $13 \%$ ethane present. This is about the ratio to be expected if the nethane cylinder (supplied by the ohio Chemical Co.) was actually filled with naturil gas.

The Neutron Spectrum

linergy intervils were chosen to be $0.5 \mathrm{MV}$ ride for the methane and the ethune datia and 0.2 IV wide for the hydrogen datil. The boundary of each interval of the neutron spectrum was reduced by $6.3 \%$ to obtain intervals in which the number of recoil protons could be counted. I reduction of $3.5 \%$ was required beciuse protons were meesured out to $15^{\circ}$, and hence the energies of the protons were on the averige less by thit anount than the energies of the neutrons which produced them. The further reduction was required because of the apparont unsymmetrical stragiling observed when the spectrurn of monochromatic neutrons from Cl2 $\mathrm{D}$ was measured in the same cloud chamber. The number of recoil prot on tracks in ench energy interval wis then corrected for (a) the cross-section for $n-p$ collision, (b) geometrical factors, and (c) rall effects in the cloud chanber, to obtain the number of ncutrons in the corresponding energy interval.

The cross-section for collision of a neutron with a hydrogen nucleus has been given as a Iunction of energy by Kittel and Bieit3. Their values Were used, the correction factor being norm:llized to 0:1e for a recoil proton of $1 n$ min ringe in tho cloud chimber nixture.
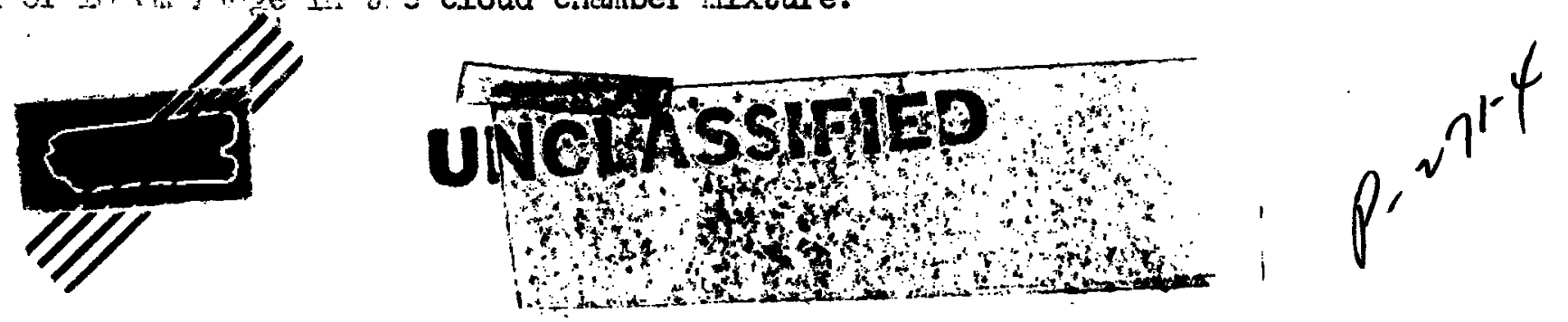


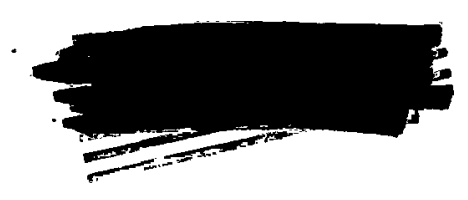

\section{UNCLASSIFIED}

$-3-$

Longer recoil protons have smaller probability of being measured because they leave the chamber at the distant will or at the top and botton of the illuminated space. If they left the side of the stereoscopic space they could still be messured in one of the photosriphs. Hence two geometricsl corrections were required. The first is for the finite length of the chimber and is ziven by

$$
i_{I}=\left(1 / L_{0}\right)-I /\left(L_{0} \text { f } \lambda-S\right)
$$

where $h_{L}$ is the probability of observing a track of length $s$ in the rectangular illuminated area of the cloud chamber of diameter $\lambda$, (see appendix, Fig. 1 ). $I_{0}$ is the distance from the source to the chamber. $L_{0}$ was 14 clil for all dati, and $\lambda$ was taken as $21 \mathrm{~cm}$ because traciss were not neasured near the wills.

form

The correction for the finite depth of the chumber is of the simple

$$
W_{d}=I-\left(4 s \sin \theta_{0}\right) / 3 \pi d
$$

if the source is infinitely distant from the chamber. $\theta_{0}$ is the maximum angle that the recoil protion can maike vith the neutron and still be acceptable for measurement. $\theta_{0}$ was $15^{\circ}$ in the present experinent; and $d$, the depth of the illuminated portion of the chamber, was $5 \mathrm{~cm}$. The ibove simple expression was the correction factor used for our preliminary reports on the neutron spectrum. However, if the neutron source is not infinitely distant, use of the above expression discriminates against the longer tracks. Evidence that this discrimination was appreciable was the failure of the corrected spectrun taken in the hydrogen run to agree satisfactorily with the corrected methane and ethane data in the region of overlap. Therefore, we undertook to calculate the correction factor which should be used if the neutron source is at finite distance. The derivation of this correction is given as an appendix to this report. The resulting correction factor for our particular experimental arrangement has been evaluated, normalized to one for a $10 \mathrm{~cm}$ proton recoil in the chamber, and plotted in Fig. 2. The difference between the new and the old correction factor is quite appreciable.

After the methane data was finished, difficulty was found in ineasuring tracks which went out of the stereoscopic space on one side so these tracks were excluded in the hydrogen and ethane data. Hence an additional correction was applied to these data. This correction for the finite width of the stereoscopic area is of the same form as the new depin correction (see appendix) except that proper allowance must be made for the fact that tracks leaving one side of the stereoscopic space could still be measured on the other photograph. This correction is also plotted in Fice. 2 .

The correction for wall effects was based on our measurements ${ }^{2}$ of the monochromatic neutrons from $C^{12} / \mathrm{D}$.
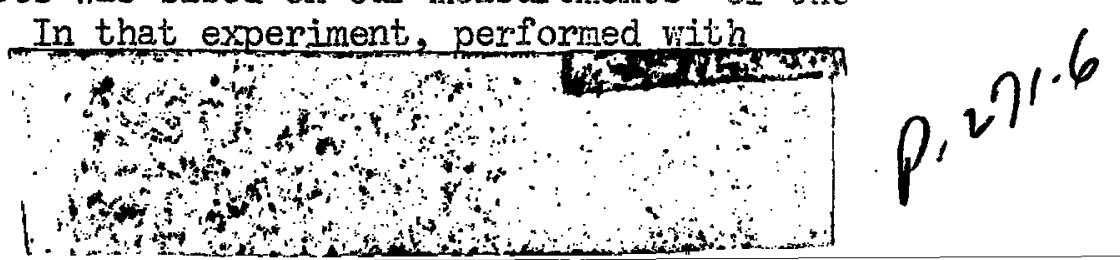


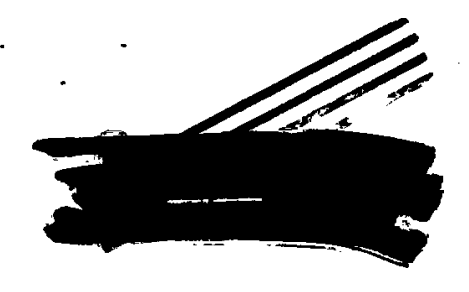

the same cloud chamber, a flat baciground was observed on the low energy side of the monochromatic group. The baciground was believed to be caused by either elastic or inelastic scattering of the neutrons in the walls of the cloud chamber, but its interpretation is not relevant to the present experiment. The number of neutrons in the bacikground was one sixth of the nuraber in the group. (This estinate was made after the data given in reference (2) was recompleted using the new geometry correction which is derived in the appendix of this report.) The assumption was made that this ratio would not change much with the energy of the neutron group. The correction is small for high energies, but it became rather large for the low energies reached in the hydrogen run, and was 20\% for the lowest energy interval.

The numbers of recoil protons in each energy interval is tabulated in Tables I, II, and III for methane, hydrogen, and ethane respectively. The corrections are also given and the number of neutrons in each interval.

Table I

Spectrum in iethane

\begin{tabular}{|c|c|c|c|c|c|c|c|}
\hline \multirow{2}{*}{$\begin{array}{c}\text { Energy } \\
\text { Interval } \\
\text { i.JV }\end{array}$} & \multirow{2}{*}{$\begin{array}{l}\text { Nio. } \\
\text { Recoil } \\
\text { Tracks }\end{array}$} & \multirow{2}{*}{$\begin{array}{l}\text { Ho. } \\
\text { Beck- } \\
\text { ground }\end{array}$} & \multicolumn{4}{|c|}{ Corrected for } & \multirow[b]{2}{*}{$\begin{array}{l}\text { Relative } \\
\text { No. of } \\
\text { Neutrons }\end{array}$} \\
\hline & & & $\begin{array}{l}\text { Back- } \\
\text { ground }\end{array}$ & $\begin{array}{l}\text { Cross } \\
\text { section }\end{array}$ & Geometry & $\begin{array}{l}\text { l.all } \\
\text { effects }\end{array}$ & \\
\hline $\begin{array}{l}1.0-1.5 \\
1.5-2.0 \\
2.0-2.5 \\
2.5-3.0 \\
3.0-3.5 \\
-3.5-4.0 \\
4.0-4.5 \\
>4.5\end{array}$ & $\begin{array}{r}21 \\
18 \\
8 \\
8 \\
8 \\
3 \\
3 \\
3\end{array}$ & Spe & $\begin{array}{r}21 \\
15 \\
8 \\
8 \\
8 \\
3 \\
3 \\
3 \\
\text { ctrum }\end{array}$ & $\begin{array}{c}11.4 \\
9.7 \\
5.9 \\
6.6 \\
7.3 \\
3.0 \\
3.3 \\
\text { in Hydro }\end{array}$ & $\begin{array}{l}3.0 \\
2.9 \\
2.1 \\
2.9 \\
4.2 \\
2.5 \\
4.2 \\
\text { gen (Table }\end{array}$ & $\begin{array}{l}2.4 \\
2.5 \\
1.8 \\
2.6 \\
4.0 \\
2.4 \\
4.1 \\
\end{array}$ & $\begin{array}{l}2.4 \pm 0.4 \\
2.5 \pm 0.7 \\
1.8 \pm 0.5 \\
2.6 \pm 0.7 \\
4.0 \pm 1.0 \\
2.4 \pm 1.0 \\
4.1 \pm 1.6\end{array}$ \\
\hline $\begin{array}{l}0.4-0.6 \\
0.6-0.8 \\
0.8-1.0 \\
1.0-1.2 \\
1.2-1.4 \\
1.4-1.6 \\
1.6-1.8 \\
1.8-2.0 \\
>2.0\end{array}$ & $\begin{array}{r}34 \\
30 \\
21 \\
25 \\
11 \\
7 \\
4 \\
2 \\
7\end{array}$ & $\begin{array}{l}3 \\
3 \\
1\end{array}$ & $\begin{array}{r}28 \\
24 \\
19 \\
25 \\
11 \\
7 \\
4 \\
2 \\
7\end{array}$ & $\begin{array}{r}14.8 \\
14.7 \\
13.1 \\
19.1 \\
9.1 \\
6.2 \\
3.3 \\
2.0\end{array}$ & $\begin{array}{l}2.9 \\
3.3 \\
3.5 \\
6.0 \\
3.6 \\
3.2 \\
2.8 \\
2.2\end{array}$ & $\begin{array}{l}1.9 \\
2.4 \\
2.7 \\
5.4 \\
3.1 \\
2.7 \\
2.3 \\
1.8\end{array}$ & $\begin{array}{l}1.9 \pm 0.5 \\
2.4 \pm 0.6 \\
2.7 \pm 0.6 \\
5.4 \div 0.8 \\
3.1 \pm 0.7 \\
2.7 \div 0.8 \\
2.3 \div 0.9 \\
1.8 \div 1.1\end{array}$ \\
\hline
\end{tabular}

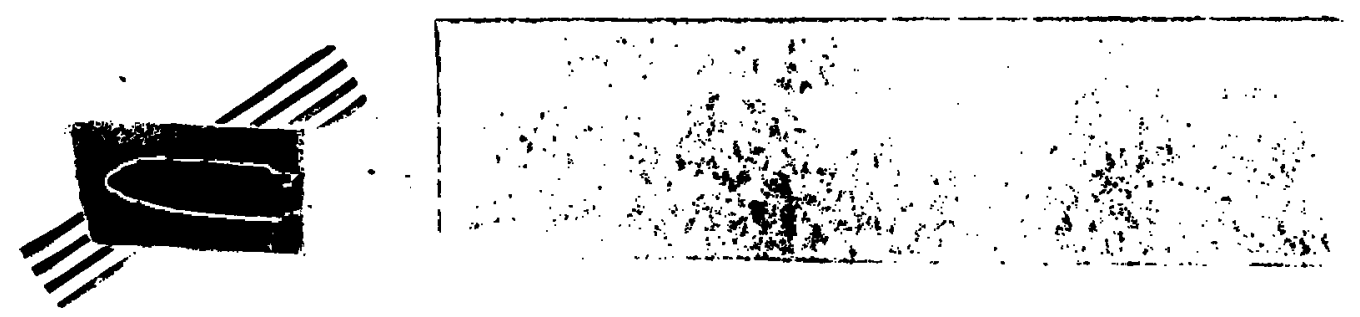




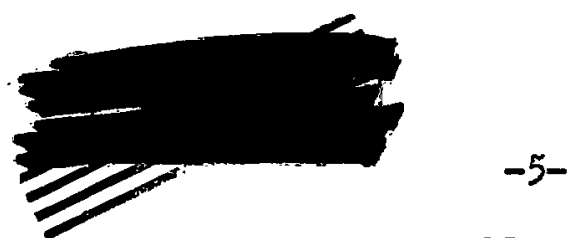

Table III

Spectrum in lethane

\begin{tabular}{|c|c|c|c|c|c|c|c|}
\hline \multirow{2}{*}{$\begin{array}{l}\text { Energy } \\
\text { Interval } \\
\text { I.iv }\end{array}$} & \multirow{2}{*}{$\begin{array}{l}\text { No. } \\
\text { Recoil } \\
\text { Tracks }\end{array}$} & \multirow{2}{*}{$\begin{array}{l}\text { Ho. } \\
\text { Bacir- } \\
\text { ground }\end{array}$} & \multicolumn{4}{|c|}{ Corrected for } & \multirow[b]{2}{*}{$\begin{array}{l}\text { Relative ivo. } \\
\text { of Neutrons }\end{array}$} \\
\hline & & & $\begin{array}{l}\text { Back- } \\
\text { ground }\end{array}$ & $\begin{array}{l}\text { Cross } \\
\text { section }\end{array}$ & Geometry & $\begin{array}{l}\text { Viall } \\
\text { Iffects }\end{array}$ & \\
\hline $\begin{array}{l}1.0-1.5 \\
1.5-2.0 \\
2.0-2.5 \\
2.5-3.0 \\
3.0-3.5 \\
3.5-4.0 \\
4.0-4.5 \\
4.5-5.0 \\
5.0-5.5 \\
>5.5\end{array}$ & $\begin{array}{r}22 \\
20 \\
14 \\
10 \\
5 \\
5 \\
1 \\
1 \\
2 \\
1\end{array}$ & (1) & $\begin{array}{r}22 \\
17 \\
14 \\
10 \\
8 \\
5 \\
1 \\
1 \\
2 \\
1\end{array}$ & $\begin{array}{r}10.1 \\
9.3 \\
8.3 \\
6.9 \\
6.2 \\
4.3 \\
0.9 \\
1.0 \\
2.2\end{array}$ & $\begin{array}{l}2.0 \\
2.1 \\
2.2 \\
2.1 \\
2.2 \\
1.9 \\
0.5 \\
0.8 \\
2.7\end{array}$ & $\begin{array}{l}1.6 \\
1.8 \\
2.0 \\
1.9 \\
2.1 \\
1.8 \\
0.5 \\
0.8 \\
2.7\end{array}$ & $\begin{array}{l}1.6 \pm 0.3 \\
1.6 \pm 0.4 \\
2.0 \pm 0.4 \\
1.9 \pm 0.4 \\
2.1 \pm 0.5 \\
1.8 \pm 0.6 \\
0.5 \pm 0.4 \\
0.8 \div 0.6 \\
2.7 \pm 1.3\end{array}$ \\
\hline
\end{tabular}

A final result for the energy spectrum of fission neutrons was obtained by adding the methane data to the ethane deta, the latter being weighted by a factor of two. The two sets of data were based on abservation of about equal numbers of tracks, but for a given neutron energy the range of the recoil proton is much less in the ethane and hence uncertainties in the geometrical corrections are less. The number of neutrons between $0.5-1.0$ ifv was obtained from the hydrogen data by using the number of neutrons between 1.0 and 2.0 viv to normalize the value. The final results are given in Table IV and plotted in Fig. 3 .

Table IV

Energy Interval (MV)

Relative No. of Neutrons

$0.5-1.0$
$1.0-1.5$
$1.5-2.0$
$2.0-2.5$
$2.5-3.0$
$3.0-3.5$
$3.5-4.0$
$4.0-4.5$

$4.6+0.9$

$5.6 \mp 0.7$

$6.1 \pm 1.3$

$5.8 \pm 0.9$

$6.4 \mp 1.1$

$8.2 \mp 1.5$

$6.0 \mp 1.5$

$5.1 \pm 1.8$

The error indicnted in Tables I-IV is the srobable error besed c. the nubor of recoil proton tracks observed.

\section{Discussion}

The switroi spactrun is to a first approximation flat between $0.5 \lambda$ and $4.5 \mathrm{H}$.IV. It appears to fall off somewhat at the low energy end, but this point is not emphasized because the anount which it falls off depends upon the wall coveroon which may have been overestinated to soine exient.

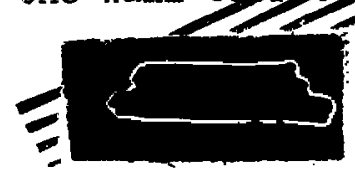




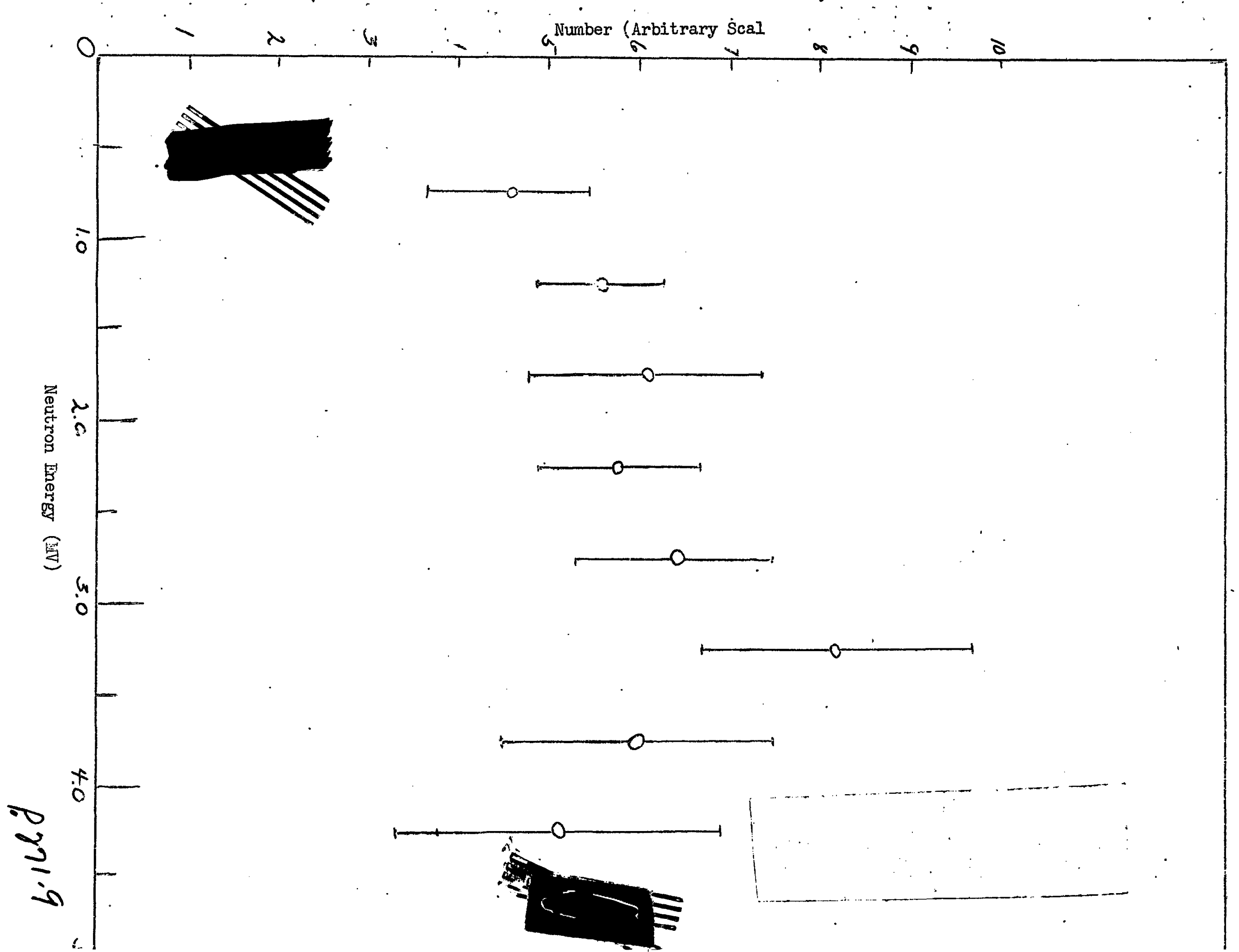


Inelastic scattering in the uranium sphere itself has not been considered in working out the results. If it is as large as has been reported, the true spectrum may slope upward with increasing energy in the energy region here considered.

For our experimental arrangement (Fig. 1), scattering of the fission neutrons in the uranium itself (either elastic or inelastic) would tend to reduce the number of neutrons observed in the cloud chamber. This reduction would exist because the majority of the fission neutrons are produced in the side of the sphere farthest distant frorn the cloud chamber. The error caused thereby cannot be calculated, but it is unlikely to be serious unless the scattering cross-section of neutrons by uranium is large and varies rapidly with energy.

The presence of the paraffin does not distort the spectrum of neutrons from uranium because it is all "behind" the uraniun, and the uranium neutrons would have to be scattered several times in the paraffin to reach the cloud chamber. Also the dimensions of the paraffin are only of the order of the mean free path of fast neutrons. lie checked the effect of the paraffin by measuring the increase in ionization in a nethane filled electroscope when paraffin was put "behind" the lithiun target. Apparently, with the amount of paraffin which we have used, less than several percent of the measured tracks would be of too low energy.

It is certain that the spectrum of fission neutrons extends to energies considerably above $4.5 \mathrm{iJV}$. In each set of data, the number of tracks observed in excess of an upper energy limit have been recorded. These were tracks which started in the gas and were within $15^{\circ}$ of the forward direction, but some of them went out of the chamber because of their high energy. Although their numbers were small, they represent a large number of high energy neutrons because the probability of observing such long tracks was very small. In addition, recoil tracks were observed which apparently started in a film of moisture in the front wall and went all the way across the chamber when it was filled with ethane. These traciss require the presence of neutrons of energy greater than 7.6 IV in the fission spectrum.

Because of the high energies involved, the measurement of proton recoil tracks in a cloud chamber cannot give complete results for the spectrum of fission neutrons. A photographic plate might be used to record proton recoil tracks, or a cloud chamber could be used if conditions were such that the tracks of recoiling helium nuclei were measured.

\section{References:}

1. Livingston and Bethe, Rev. 10.1. Phys19, 276, (1937)

2. T. E. Bennett and H. T. Richards, CF Report No. 206

3. Kittel and Breit, Phys. Rev.56, 744

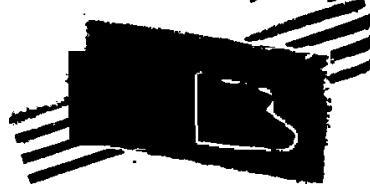


A GEONETRY CORRECTION FOR CLOJD CHAIIBER DATA IHENT THE NEUTRON SOURCE IS NOT. INFINITELY DISTANT

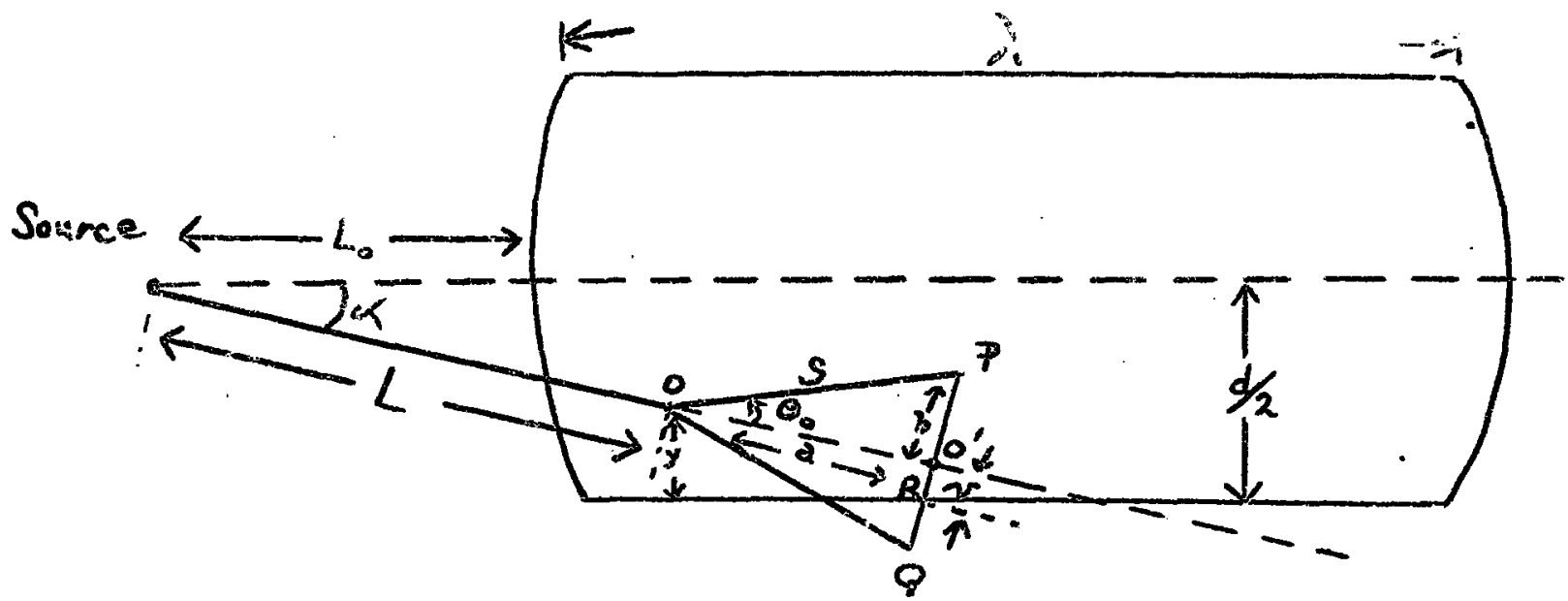

Fig. 1

Notation:

I -- distance from source to scattering center 0

$\mathrm{L}_{\mathrm{O}^{-}}$- minimum value of $\mathrm{L}$

y-- distance from edge of illuminated section (bottom or side) to scattering center 0

$S$ - range in cloud chamber of the recoil protion $=O P$

$\theta$ - angle of recoil proton to incident neutron

$\theta_{0^{-}}$maximum acceptable value of $\theta$

a $--S \cos \theta_{0}$

$\mathrm{b}-\mathrm{S} \sin \theta_{0}$

d -- depth (or width) of illuminated portion of cloud chamber

$\lambda$-- length of illuminated portion of cloud chamber

$\alpha$ - angle which the neutron makes with respect to a line from the source which bisects the chamber.

$v-O$ OR

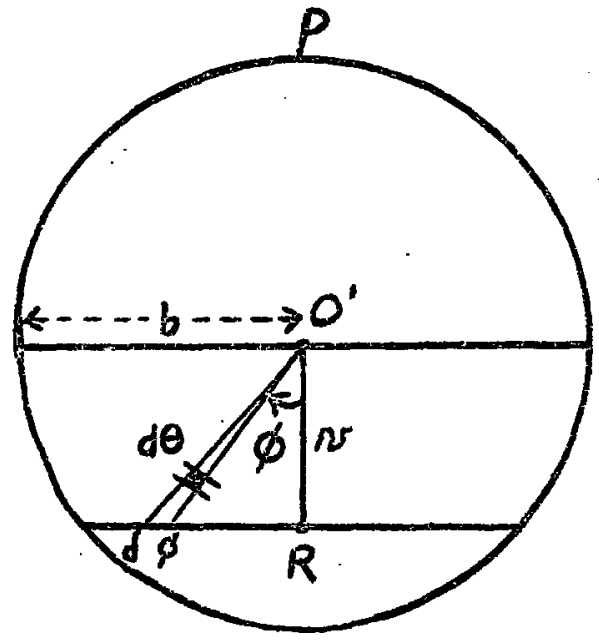

Q

Fig. 2 - End view of PO'Q of Fig. 1
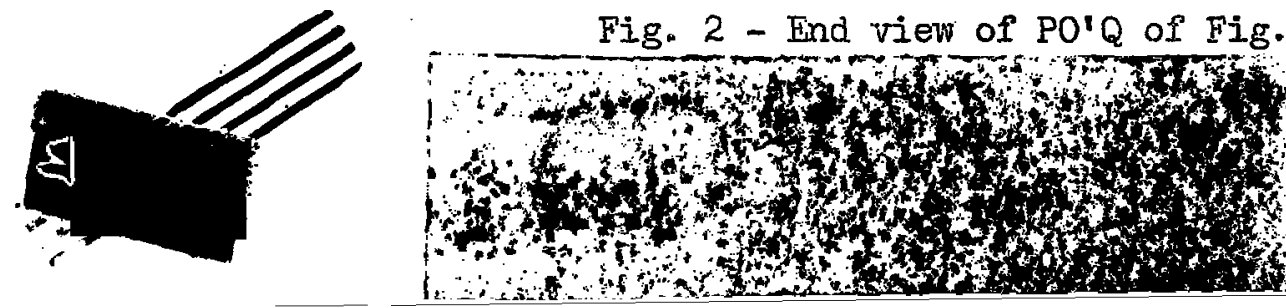
Let $k \sigma$ be the number of recoil protons scattered from 0 into the solid angle subtended by circle $P Q$, and let $k \sigma$ be the number of recoil protons scattered froin $O$ into the solid angle subtended by circle segment PO'R. Then the probability that a recoil proton, scattered from 0 into the solid angle subtended by circle PQ, will end within the illuminated portion of the chamber (and hence be acceptable for measurement) is

$$
\mathrm{w}=\mathrm{k} \sigma^{\prime} / \mathrm{k} \sigma=\sigma^{\prime} / \sigma
$$

But

Hence

$$
\mathbf{k} d \sigma=\cos \theta \sin \theta d \theta d \phi
$$

$$
k \sigma=\int_{0}^{2 \pi} \int_{0}^{\theta_{0}} \cos \theta \sin \theta d \theta d \phi=\pi \sin ^{2} \theta_{0}
$$

From Fig. 1 and Fig. 2 (appendix),

$$
\begin{aligned}
k \sigma^{\prime} & =\frac{k \sigma}{2}+2\left(\int_{0}^{\phi} \int_{0}^{\theta_{0}}+\int_{0}^{\phi I} \Gamma_{0}^{\theta_{I I}}\right) \cos \theta \sin \theta d \theta d \phi \\
& =\frac{k \sigma}{2}+\sin ^{2} \theta_{0} \sin ^{-1}\left(\frac{v}{b}\right)+\frac{v}{\sqrt{a^{2}+v^{2}}} \tan -1\left(\frac{b^{2}-v^{2}}{a^{2}+v^{2}}\right)^{\frac{1}{2}}
\end{aligned}
$$

Since

$$
\begin{aligned}
& \sin \phi_{I}=\frac{v}{b} \\
& \sin \theta_{I I}=\left(1+\frac{a^{2}}{v^{2}} \cos ^{2} \phi\right)^{-\frac{1}{2}} \\
& \tan \phi_{I I}=\left(\frac{b^{2}-v^{2}}{v^{2}}\right)^{\frac{1}{2}}
\end{aligned}
$$

Therefore:

$$
\mathrm{W}=\frac{\mathrm{k} \sigma^{\prime}}{\mathrm{k} \sigma}=\frac{1}{2}+\frac{1}{\pi} \sin ^{-1}\left(\frac{v}{b}\right)+\frac{1}{\pi \sin ^{2} \theta_{0}} \frac{v}{\sqrt{a^{2}+v^{2}}} \tan ^{-1}\left(\frac{b^{2}-v^{2}}{a^{2}+v^{2}}\right)^{\frac{1}{2}}
$$

The above expression is valid for $|v| \leq b$; and because of the relationship between $\mathrm{v}$ and $\mathrm{y}$ (see below), it holds for $0 \leq \mathrm{y} \leq \mathrm{y}^{\dagger}$. From Fig. I (appendix)

and

$$
v=\frac{d}{2} \sec \alpha-(L+a) \tan \alpha
$$

$$
\sin \alpha=(d / 2-y) / L
$$

For the usual experimental geometry, it is a good approximation to set $\cos \alpha=1$ in expression (7). The resulting expression combined with ( 8 ) gives

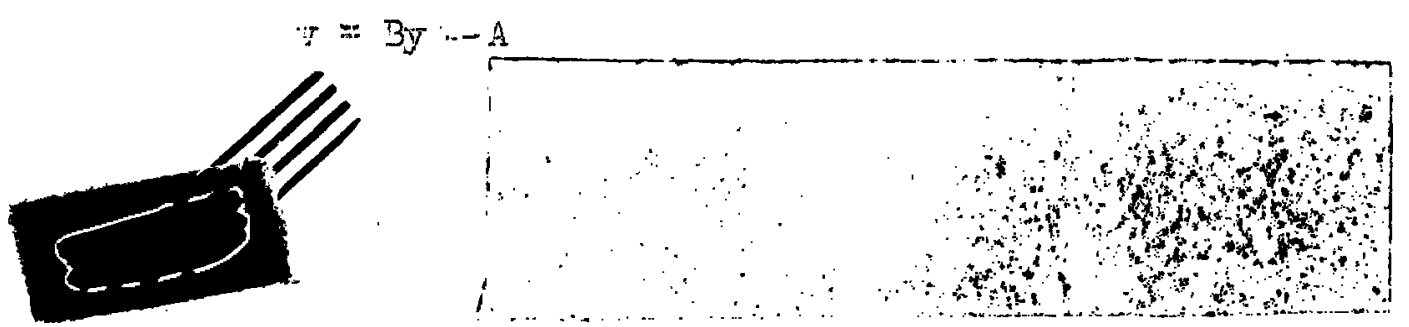


where

$$
\begin{aligned}
& A=\mathrm{da} / 2 \mathrm{~L} \\
& B=(L+a) / L
\end{aligned}
$$

Therefore, when $v=b$;

$$
y\left(=y^{\prime}\right)=(b+A) / B
$$

The expression for the average value of $\mathrm{w}$ for scattering centers between $y=0$ and $y=d / 2$,

$$
\langle i i\rangle_{a v}=(2 / d)\left[y^{\prime} \bar{W}+\left(d / 2-y^{\prime}\right) \times 1\right] \text {, }
$$

requires that we first know the mean value of $W$ in the interval $0 \leq \mathrm{y} \leq \mathrm{y}^{3}$. This mean value of $W$ is denoted by $W$ in expression (13).

For the calculation of $\overline{\mathrm{W}}$ we have

$$
\overline{\mathrm{W}}=\left(1 / \mathrm{y}^{\prime}\right) \int_{0}^{y^{\prime}} \mathrm{Wy}=1 /(\mathrm{b}+|\mathrm{v}|) \int_{-\infty}^{b} \mathrm{w} d v
$$

and since by $(9),\left(-v^{1}\right)=A$ when $y=0$, the result is.

$$
\bar{w}=1 /(b+A) \int_{A}^{b} d v
$$

All terms of the last integral, (15), are easily evaluated except the one involving

$$
\int f(v) \tan -1\left[\left(b^{2}-v^{2}\right) /\left(a^{2}+v^{2}\right)\right]^{\frac{1}{2}}
$$

However, the maximum value of the arctangent function in (16) occurs when $\mathrm{v}=0$. For the present experiment this maximum value is the tangent of 150. For angles less than $15^{\circ}$ there will be less than a $2 \%$ difference between the angle and its tangent. Hence to integjate (16), we replace the arctangent function by the tangent itself. Expression (15) then results in

$\bar{V}=\frac{1}{2}+\frac{1}{\pi(b+A)}\left[\frac{b \pi}{2}-A \sin ^{-1}\left(\frac{A}{b}\right)-\sqrt{b^{2}-A^{2}}\left(1+c c^{2} \theta_{0}\right)+\frac{S}{2 \sin ^{2} \theta_{0}} \log \frac{S \pm \sqrt{b^{2}-A^{2}}}{S-v^{2}-A^{2}}\right]$

Substituting (17) and (12) in (13) gives

$\left\langle V_{a v}=1-\frac{A}{d B}-\frac{2 A}{\pi a^{B} B} \sin ^{-1}\left(\frac{A}{b}\right)-\frac{2 \sqrt{b^{2}-A^{2}}}{\pi d B}\left(1+\csc ^{2} \theta\right)+\frac{S}{\pi d B \sin ^{2} \theta} \log \frac{S+\sqrt{b^{2}-A^{2}}}{S-\sqrt{b^{2}-A^{2}}}\right.$

Since $A$ and $B$ are eech functions of $I$, expression (18) is not yet applicable to the obsarved distribution of recoi? protons. Becsuse it is difficult to average (18) with respect to $\mathrm{I}$, the following proceciure was adopted. First, average values of $L$ (nrejglnted according to the inverse
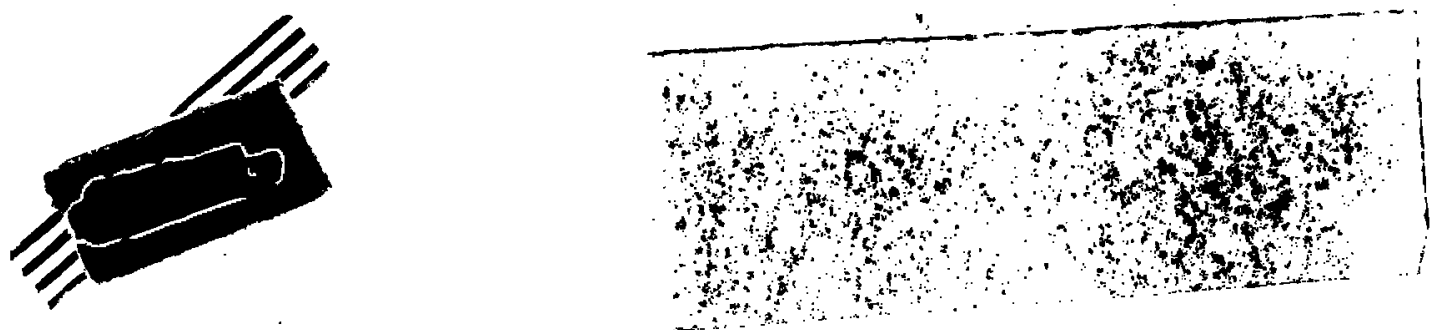


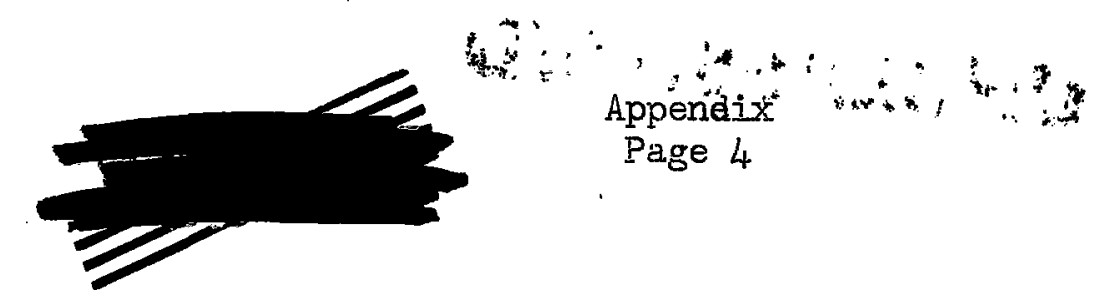

square law) for five different track lengths, $S$, were computed:

$$
\bar{L}=1 /(\lambda-S) \int_{L_{0}}^{L_{0}+\lambda-S}\left(\mathrm{k} / \mathrm{L}^{2}\right) \mathrm{L} d \mathrm{~L}-(\mathrm{k} / \mathrm{A}-\mathrm{S}) \log \left(\frac{\mathrm{L}_{0}+\lambda-S}{\mathrm{~L}_{0}}\right)
$$

The constant $k$ is determined by the condition that $\bar{I}=I_{0}$ when $S=\lambda$. The result is

$$
\bar{I}=\left[\frac{I_{0}\left(I_{0}+\lambda-S\right)}{\lambda-S}\right] \log \left(\frac{L_{0}+\lambda-S}{I_{0}}\right)
$$

The mean values of I thus calculated were then used in (18) to compute $\langle W\rangle$ ar for five different track lengths $S$. The resulting correction factors normalized to one $1 \mathrm{jr}$ a $10 \mathrm{~cm}$ treack are plotted on Fig. 2 of the main portion of this repori.
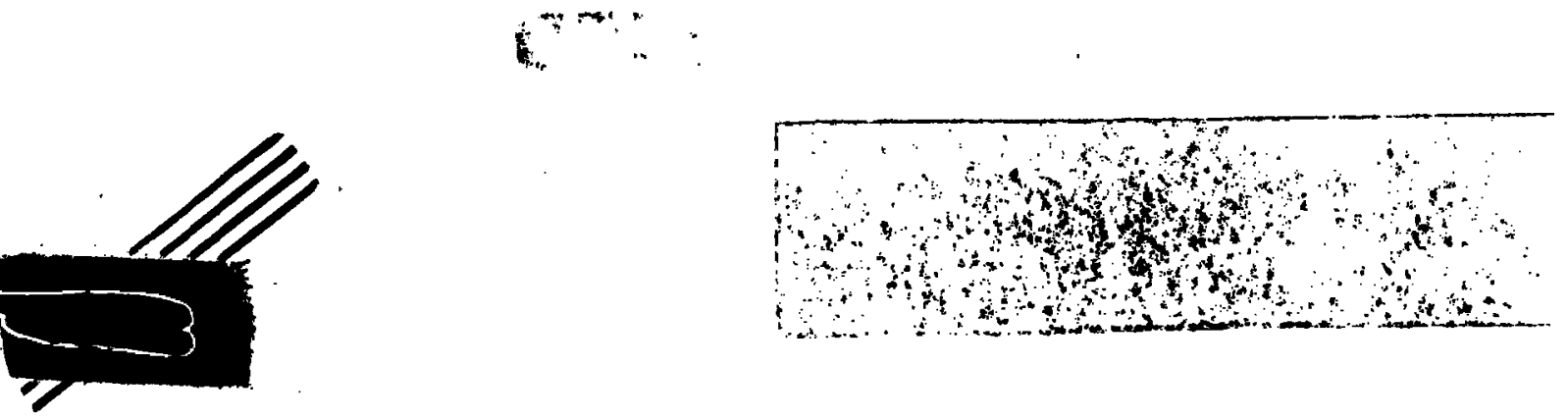

$2,2^{1.14}$ 